\title{
WHOLE BLOOD VISCOSITY CHANGES AT COAGULATION UNDER COUETTE FLOW
}

\author{
Ivan Ivanov \\ National Sports Academy "Vassil Levski”, Sofia, Bulgaria
}

\begin{abstract}
Summary
The aim of the study is to observe how blood viscosity was changed in time in Couette blood flow at coagulation and under steady flow at two low shear rates $0,0237 \mathrm{~s}^{-1}$ and $0,0596 \mathrm{~s}^{-1}$. Blood samples from one donor with different hematocrits were used and $2 \%$ aqueous solution of $\mathrm{CaCl}_{2}$ was added to initiate coagulation. The whole blood viscosity increases with the progress of coagulation at Couette flow at both shear rates. For detailed estimation of blood clot structure changing in time, three time parameters were introduced: i) whole time duration; ii) initial clot formation time; iii) clot formation time. All these time characteristics of coagulation reveal shear rate and hematocrit dependence. A higher shear rate determines shorter values for them. Higher hematocrit has a tendency for accelerated coagulation.
\end{abstract}

Key words: blood coagulation, whole blood viscosity, shear rate, Couette flow

\section{Introduction}

Blood coagulation is a phenomenon consisting of a number of conversions of plasma constituents which form blood clot. This complex biochemical process consisting of numerous enzymatic chain reactions is influenced by plasma compounds, endothelial and blood cells and by flow conditions. The key role is plasma fibrinogen transformation into structural fibrin. The result is a complicated net formation in which the blood cells are joined (Ivanov, 2006; Antonova, 2001).

The significance of blood flow in thrombosis and hemostasis was recognized as early as the 19th century, as flow being one of the components of the famous Virchow's triad (Lowe, 2003/2004). Two basic hemostatic mechanisms - platelet plug formation and blood coagulation, are known to depend differently on the flow conditions. Platelet adhesion and aggregation require high blood flow velocities, while fibrin deposition occurs better in slowly flowing blood (Shibeko et al., 2010; Baumgartner, 1973; Okorie et al., 2008). Moreover, recent data suggest that fibrin clot formation is inhibited by flow in a threshold-like manner (Shen et al., 2008). This can be observed in vivo by the formation of fibrin-rich red thrombi containing erythrocytes in the veins (where shear rate is low) and of platelet-rich white thrombi in the arteries (Brogan, 2002). The above mentioned results emphasize the blood flow importance for hemostasis and fibrin deposition.

The initial microstructure of the fibrin clone con- sists of a mixed network of entangled and branched fibrin threads. Fibrin thread thickness is a marker for the presence of a certain type of pathology. Fiber mesh of thinner threads with more branching forms a denser thrombus with less permeability. Such a microstructure is known to be directly associated with a thromboembolic disease (Undas et al., 2009; Mills, 2002; Jörneskog et al., 1996).

The time development of the thrombus microstructure is associated with a significant change in the viscoelastic properties of the blood (a measure of the viscous and elastic blood properties). Clot viscoelastic properties are among the most sensitive measures for fibrin polymerization and thrombus structure (Weisel, 2004).

The coagulation process changes the physical properties of blood from a viscoelastic fluid to a viscoelastic solid. The important point between these two conditions has been previously defined as the gel point (GP) (Blomback, Bark, 2004; Evans et al., 2010). Before getting the GP, blood behaves as a non-Newtonian fluid. After the GP, the blood clot under flow exhibits both fluid (viscosity) and solid (elasticity) properties (Ranucci, 2014).

\section{Aim and Objectives of the study}

The aim of the study is to observe blood viscosity changes in time in Couette blood flow at coagulation and under steady flow at two low shear rates $0,0237 \mathrm{~s}^{-1}$ and $0,0596 \mathrm{~s}^{-1}$. To determine the relation between the time characteristics of coagulation, 
shear rate and hematocrit.

\section{Methods}

Normal blood from a healthy female subject, $\mathrm{Rh}+$, group 0 , conserved with $\mathrm{CPD}-\mathrm{A}_{1}$ conserving agent (in ratio $63 \mathrm{ml} / 450 \mathrm{ml}$ blood from National Centre of Transfusion Hematology, Sofia) was used in this investigation. The whole blood quantity was divided into $10 \mathrm{ml}$ volumes with different hematocrits, which were kept at temperature $4{ }^{\circ} \mathrm{C}$. To initiate coagulation $0,1 \mathrm{ml}$ aqueous solution of $2 \% \mathrm{CaCl}_{2}$ was added to the measured blood samples of $0,8 \mathrm{ml}$.

The experiments were carried out using rotational viscometer LS30 Contraves, which uses Couette flow geometry, between two coaxial cylinders. The whole blood viscosity (WBV) changes with the evolution of the coagulation process under shear flow were measured. The coagulating samples are subjected at a steady shear flow at two shear rates $0.0237 \mathrm{~s}^{-1}$ and $0.0596 \mathrm{~s}^{-1}$.

\section{Results}

The time course of coagulation process ( $\mathrm{after} \mathrm{CaCl}_{2}$ addition) was evaluated by blood viscosity recording. At the beginning of this course WBV keeps almost constant values. In case of low hematocrit values $\left(\mathrm{Hct}=28 \%, \mathrm{~T}=25^{\circ} \mathrm{C}\right.$, shear rate $\left.0.0596 \mathrm{~s}^{-1}\right)$ the WBV rises from $35,04 \mathrm{mPa}$.s in the 60-th second to $41,61 \mathrm{mPa} . \mathrm{s}$ in 510 -th seconds (fig. 1). After this period of time WBV increases intensively, reaching a maximum value and slowly decreasing with time.

For detailed estimation of blood clot structure changing, three time parameters were introduced:

- whole time duration (WTD), describes the time interval between $\mathrm{CaCl}_{2}$ addition and the maximum WBV value;

- initial clot formation time (ICFT), marks the initial time period of almost constant WBV;

- clot formation time (CFT), describes time interval of intensive WBV increase, starting at the moment when in 30 seconds WBV increases at least two-fold (fig. 1).

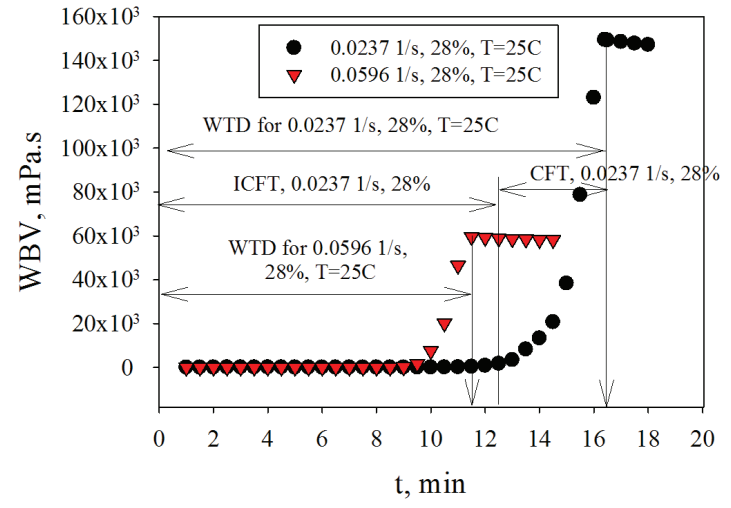

Fig. 1 Whole blood viscosity changes at coagulation at different shear rates.

These three time parameters are in the following relation:

$$
\mathrm{WTD}=\mathrm{ICFT}+\mathrm{CFT}(1)
$$

Significant shear rate dependence of WTD was obtained. The higher shear rate $0,0596 \mathrm{~s}^{-1}$ led

to a shorter WTD parameter in comparison with $0,0237 \mathrm{~s}^{-1}$ (fig. 2).

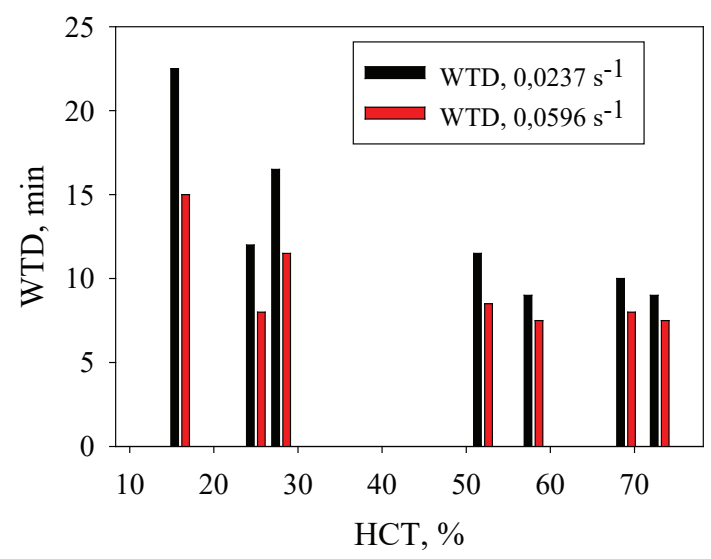

Fig. 2 Whole time duration (WTD) changes with hematocrit.

The other two measured time parameters (ICFT, CFT) also show a shear rate and hematocrit subordination (Fig. 3). Higher shear rate determines shorter CFT and ICFT intervals. As the hematocrit increases, there is a tendency for an accelerated process of thrombus formation (Fig. 3). 


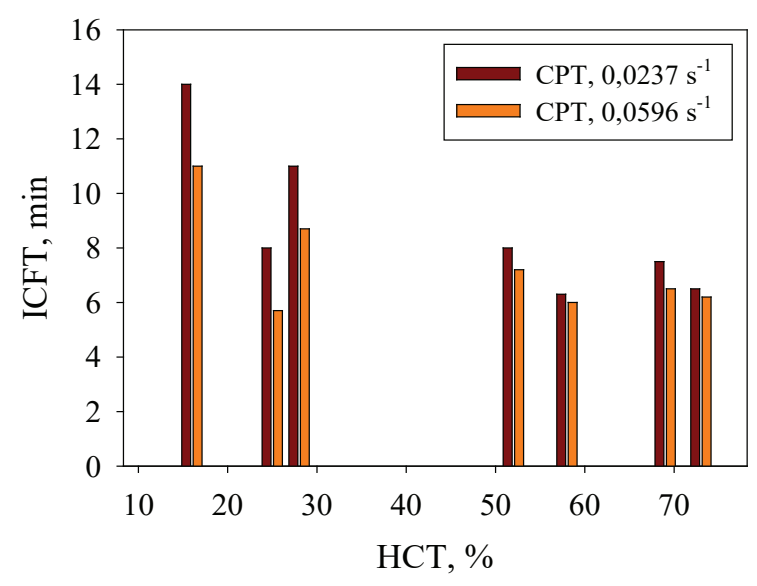

a.)

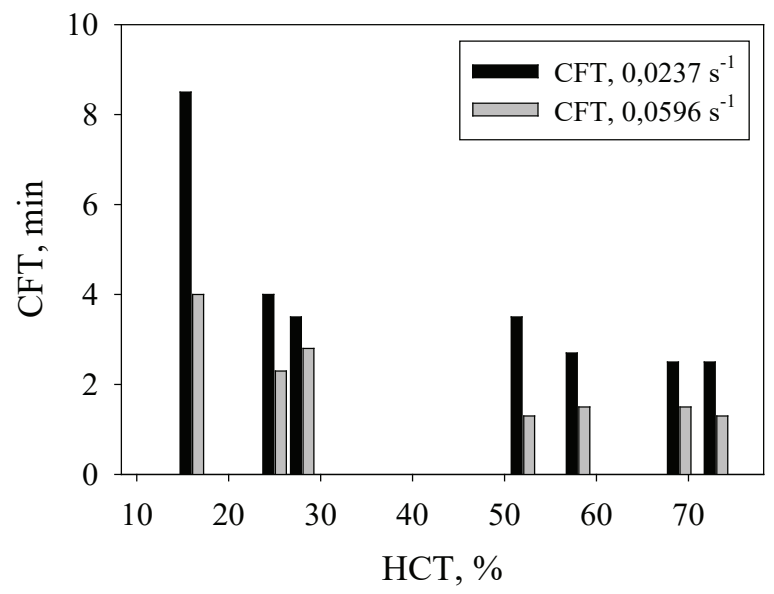

b.)

Fig. 3 a). Initial clot formation time (ICFT) at different hematocrits and shear rates; $b$ ). Clot formation time (CFT) at different hematocrits and shear rates.

\section{Discussion}

The obtained results show that the WBV increases with the progress of coagulation at Couette flow at both shear rates. These results confirm the data of Marco Ranucci et. al. 2014, with specification that estimated WBV in their paper was measured by cone-on-plate viscosimeter geometry at higher shear rates $\left(20 \mathrm{~s}^{-1}, 40 \mathrm{~s}^{-1}, 80 \mathrm{~s}^{-1}\right)$.

The introduced time parameters of coagulation WTD, ICFT and CFT reveal shear rate and hematocrit dependence. A higher shear rate determines shorter values for defined characteristics. These results correspond with those of Chen et al., 2013 and Sheriff et al., 2013, who demonstrate the shear rate importance for platelet adhesion and activation in coagulation process.

Higher hematocrit has a tendency for accelerated coagulation. The results confirm these of Turitto and Weiss (1980), who receive rising levels of platelet adhesion and thrombus formation as hematocrit values increase from 10 to $70 \%$ (Turitto, Weiss, 1980). These authors explain the findings as both erythrocytes and platelets contain internal stores of ADP that on release serve to enhance the activation state of platelets, and this release may partially explain the enhanced thrombus formation observed at high shear rates and high hematocrits (Turitto, Weiss, 1980; Hathcock, 2006).

This investigation raised the interest for further examinations on the relations between the factors shear rate, hematocrit, temperature and clot inner structure at Couette flow. Future studies should be oriented towards estimation of the viscoelastic properties of blood clot in oscillation regime.

\section{References}

Antonova, N. (2001), Rheological aspects of the kinetics of blood coagulation, in Proceedings of the Balkan Seminar on Rheology \& $9^{\text {th }}$ National Rheology Workshop, Sofia, Bulgaria, April 22-25, pp. 172-179.

Baumgartner, H. R. (1973), The role of blood flow in platelet adhesion, fibrin deposition, and formation of mural thrombi, in Microvasc Res, 5, pp. 167-179.

Chen, H., Angerer, J. I., Napoleone, M., Reininger, A. J., Schneider, S. W., Wixforth, A. et al. (2013), Hematocrit and flow rate regulate the adhesion of platelets to von Willebrand factor, in Biomicrofluidics 7: 64113.

Blomback, B. and Bark, N. (2004), Fibrinopeptides and fibrin gel structure, in Biophys. Chem. 112, pp. 147-151. Brogan, G.X. Jr. (2002), Bench to bedside: pathophysiology of acute coronary syndromes and implications for therapy, in Acad Emerg Med, 9, pp. 1029-1044.

Evans, P. A., Hawkins, K., Morris, R. H., Thirumalai, N., Munro, R., Wakeman, L., et al. (2010), Gel point and fractal microstructure of incipient blood clots are significant new markers of hemostasis for healthy and anticoagulated blood, in Blood 116, pp. 3341-3346.

Hathcock, J. (2006), Flow Effects on Coagulation and Thrombosis, in Arterioscler Thromb Vasc Biol. 26, pp. 1729-1737.

Ivanov, I. (2006), Observations on the blood electrical conductivity changes at coagulation and under flow, in Proceedings of 2nd Eurosummer School on Biorheology \& Symposium on Micro Mechanobiology of Cells, Tissues and Systems, Varna, Bulgaria, September 17-20, pp. 77-80.

Jörneskog, G., Egberg, N., Fagrell, B., Fatah, K., Hessel, B., Johnsson, H. and Blombäck, M. (1996), Altered properties of the fibrin gel structure in patients with IDDM, 
in Diabetologia, 39(12), pp. 1519-1523.

Lowe, G. D. O. (2003/2004), Virchow's Triad Revisited: Abnormal Flow, in Pathophysiol Haemost Thromb 33, pp. 455-457.

Mills, J. D., Ariens, R., Mansfield, M. W. and Grant, P. (2002), Altered fibrin clot structure in the healthy relatives of patients with premature coronary artery disease, in Circulation 106(15), pp. 1938-1942.

Okorie, U. M., Denney, W. S., Chatterjee, M. S., Neeves, K. B. and Diamond, S. L. (2008), Determination of surface tissue factor thresholds that trigger coagulation at venous and arterial shear rates: amplification of $100 \mathrm{fM}$ circulating tissue factor requires flow, in Blood 111, pp. 3507-3513.

Ranucci, M., Laddomada, T., Ranucci M. and Baryshnikova, E. (2014), Blood viscosity during coagulation at different shear rates, in Physiol Rep, 2 (7), pp. 1-7.

Shen, F., Kastrup, C. J., Liu Y. and Ismagilov R. F. (2008), Threshold Response of Initiation of Blood Coagulation by Tissue Factor in Patterned Microfluidic Capillaries Is Controlled by Shear Rate, in Arterioscler Thromb Vasc Biol 28(11), pp. 2035-2041.

Sheriff, J., Soares, J. S., Xenos, M., Jesty, J., Slepian, M. J. and Bluestein, D. (2013), Evaluation of shear-induced platelet activation models under constant and dynam- ic shear stress loading conditions relevant to devices, in Ann. Biomed. Eng. 41, pp. 1279-1296.

Shibeko, A., Lobanova, E., Panteleev, M. and Ataullakhanov, F. (2010), Blood flow controls coagulation onset via the positive feedback of factor VII activation by factor $\mathrm{Xa}$, in BMC Systems Biology, 4:5. doi:10.1186/17520509-4-5

Turitto, V. T. and Weiss, H. J. (1980), Red blood cells: their dual role in thrombus formation, in Science 207, pp. 541-543.

Undas, A., Zawilska, K., Ciesla-Dul, M., Lehmann-Kopydłowska, A., Skubiszak, A., Ciepłuch, K. and Tracz, W. (2009), Altered fibrin clot structure/function in patients with idiopathic venous thromboembolism and in their relatives, in Blood, 114(19), pp. 4272-4278.

Weisel, J. W. (2004), The mechanical properties of fibrin for basic scientists and clinicians, in Biophys Chem. 112 (2-3), pp. 267-276.

Corresponding author:

Assis. Prof. Ivan Ivanov, PhD, Department of Anatomy and Biomechanics,

National Sports Academy "Vassil Levski",

1700 Sofia, Bulgaria 